\title{
Arts Funding 2000
}

\section{Introduction: Taking the Pulse of Arts Funders}

This report is a snapshot of how 35 funders approach arts grantmaking in a changing world. The information is drawn from a series of interviews and conversations which, in a manner characteristic of the arts, reveal a diversity of multilayered views, raise creative and challenging questions, and offer a range of visions for the future. The fact that every funder contacted agreed to participate in the study suggests an interest in the many questions it raises. This report is not intended to provide definitive answers to these questions. Rather, it is intended to stimulate thinking and dialogue about the direction of arts funding.

The study explores changes in the objectives, focus, and approaches to arts grantmaking and the stimuli for these changes. The discussion is framed in the context of the changing climate for arts funding both within grantmaking organizations and in the broader society of which they are part. It suggests that the patterns of giving captured in grants analyses are not likely to change rapidly. However the process, purposes, definition, and scope of grantmaking, as well as its broader social context, are likely to sustain significant changes, at least for this group of grantmakers.

Change is very different depending on whether you are inside or outside of the process. Arts funders see themselves in both places, often simultaneously. Change is a force over which they have little control—changing demographics, globalization, technology, a hostile climate to the arts--something to manage, prepare for, and respond to. Change is also a dynamic force that can be catalyzed by increasing opportunities for imagination, inclusion, and participation. "We used to think the big questions were universal, now we realize they are socially constructed," observed one foundation officer. "If they are constructed they can be reconstructed."

Being inside or outside of the process of change and of civic and social life is a major concern for the funders interviewed. Much of the discussion about a changing context for arts funding related to the marginalization of the arts and-by extension-what some perceived to be an isolated role for arts grantmaking. At the same time, funders acknowledged the untapped power of the arts and creativity to help knit together an increasingly technological and global, yet fundamentally disconnected, world. The interviews were conducted during a period overshadowed by the shootings in Littleton, Colorado, and the Kosovo crisis. Not surprisingly, these events entered into some of the conversations. One funder spoke of the arts' "critical life-saving
This report is a snapshot of how 35 funders approach arts grantmaking in a changing world. 


\section{Funders are excited about future opportunities related to new wealth, while acknowledging the challenge of harnessing it to benefit} the arts. ability," while another reflected, "I think we underestimate the ability of the arts to heal people's souls."

Along with funders' deepening concern about the role of the arts in furthering the social good has come an awareness of the need for arts funding programs to demonstrate their impact. There are increasing expectations for greater efficiency, measures of success, and return. The interviews sparked discussions about leverage, which ranged from leveraging dollars to leveraging knowledge to leveraging policy. Whether the respondents believed that leverage should operate from the top down or horizontally, or whether they preferred long-term reciprocal partnerships to strategic alliances, all were concerned about making their relatively limited investments go as far as possible.

Nearly all of the 35 funders interviewed are excited about future opportunities related to new wealth, while acknowledging the challenge of harnessing it to benefit the arts. They anticipate that this new philanthropy will be increasingly personal, a trend that runs counter to sector-wide demands for greater accountability. Given the current economic climate, most of the funders are optimistic about increases in their own organizations' resources. Yet, they remain concerned about the limited scale of their funding budgets compared to the volume of requests from worthy programs and in light of competing needs.

While resources are increasing, so is the pool of potential grantees. Whereas in the past, arts funding has focused mainly on the traditional arts disciplines, many of the grantmakers in this study are now broadening the scope of their grantmaking to include other kinds of organizations and art forms. Changing definitions include arts that cross disciplinary boundaries, new forms of arts related to technology, community-based informal or unincorporated arts and cultural tourism. Although the arts field is expanding, many foundation programs are not structured to fully embrace these new definitions.

How does the changing context influence the practice of arts grantmaking? Multiple answers to this question surfaced in discussions about the change, or the deliberate lack of change, in funders' priorities, focus, and strategies. Funders were concerned about the complexity and consequences of change and how the way they go about their business may affect the field. These discussions were usually characterized by a series of contending questions, revealing the creative tensions involved in grantmaking. These tensions are embedded in the main themes that surfaced from the interviews:

Sustainability. Grantmakers seek to increase the sustainability of arts organizations and have long-term impact on their areas of focus, while identifying dynamic adaptability as a characteristic they aspire to for themselves and their grantees. They are challenged to stay "ahead of the curve," but are also urged to "stay the course." Funders are choosing different strategies to satisfy these divergent goals: longer and larger grants streamline the grantmaking process and provide the staying power required to effect change. Short-term, smaller grants, often made through intermediaries, satisfy the need to 
respond quickly when the needs are urgent; likewise, small grants to individual artists may produce a ripple effect. Capacity-building grants help grantees adapt creatively to a changing environment.

Accountability. The funders interviewed expressed strong interest in evaluation that informs practice and promotes learning. But they are uncomfortable with the process. Many assessment methods don't fit the arts well and they are concerned that evaluation may diminish the arts by measuring only their utilitarian benefits while ignoring their intrinsic power. Still, funders acknowledge that there is an increasing demand for accountability throughout the nonprofit sector. While some decry this as a preoccupation with quantifiable information, others view it as an opportunity. By demonstrating impact, they can build broader support for the arts and for arts grantmaking.

Strategic focus. Funders are increasingly seeking to develop a more strategic approach to grantmaking by focusing on a particular set of issues or disciplines in a way that can be evaluated and produce lessons for both grantmaker and grantees. Several funders described achieving strategic focus though thematic funding initiatives. There is a corresponding impulse to think holistically and look for the synergies between areas- to be open to surprises and new and unexpected ideas.

Integrated funding. Many grantmakers talked about increasing their impact by integrating their funding through collaborations across arts and non-arts programs (for example, education, environment, and community development) within their organizations. While integrated funding is an attractive goal, they acknowledged that it is difficult to accomplish. Moreover, there is a risk that integrated funding may set impossible goals, raising expectations for the arts to solve society's most intractable problems. Another risk involves compromising the integrity of arts programs.

Artists and the creation of new work. Many of the funders interviewed are concerned that the move toward integrated funding and an increased emphasis on outcomes will result in less attention to the need for supporting artists and artmaking. They identify funding to individual artists as a significant gap. While there is an observable shift in some grantmakers' perspective toward a greater emphasis on building audiences, there is a parallel fear that if the generative part of the arts ecosystem remains fragile, no part of the system can function.

Proactive or responsive. Grantmakers feel the tension between proactive and responsive grantmaking and often employ both approaches for different programs. Generally, local grantmaking programs experience more pressure to be responsive than regional or national programs.

Influence of other sectors. Grantmakers are drawing lessons from other sectors, including business and the social sciences, to inform their approaches to grantmaking. Examples included ethnography, demographics, indicators, and other forms of research; and a venture capital approach and other commercial models. However, there is a

\author{
Grantmakers are drawing \\ lessons from other sectors to \\ inform their approaches to \\ grantmaking. However, there \\ is a question about whether \\ all of these approaches are \\ well-suited to the arts.
}


question about whether all of these approaches are well-suited to the arts. For example, arts grantmakers caution that their goals differ significantly from those of venture capitalists, for whom profit is the primary outcome.

Growing inequities and shifting power. Several funders acknowledged that power is a key, and often unspoken, element of philanthropy. In the context of a growing gap between haves and have nots, some funders are concerned with the nature of their relationship with grantees and the larger civil society within which they operate. These funders are re-examining their values in a context of change and seeking to develop approaches to philanthropy that will more effectively benefit the people they are intending to serve. They are also examining whether their internal practices are consistent with their values.

Finally, in looking forward, funders envisioned a role for grantmakers as part of an interdependent system made up of more than foundations and corporate giving programs. They expressed a need to better engage with government funding sources, business, and other nonprofits, and with artists, arts service organizations, and the cultural infrastructure-all key elements of the support system. In the view of most funders, the arts sector is most effective when connected to the social systems within communities that are an essential part of their sustainable support. 